\title{
A NARRATIVA GRÁFICA ENQUANTO MEDIUM
}

\author{
Eduardo Antonio Souza, Eva Rolim Miranda e Gentil Porto Filho
}

narrativa gráfica, medium, comics, literatura infantil, livros ilustrados. graphic narrative, medium, comics, children's literature, picturebooks.
Os comics e os livros ilustrados possuem campos de estudo e bases teóricas bastante distintos, entretanto chegam a formulações sobre seus objetos que são bastantes próximas entre si graças à similaridade formal dos artefatos analisados. Argumentando que ambos operam segundo um mesmo medium, o das narrativas gráficas, este artigo busca conciliar os comic studies e a literatura infantil, além de utilizar conceitos oriundos da crítica de arte a fim de diferenciar os parâmetros e convenções do medium. Por fim, propomos parâmetros para a análise das narrativas gráficas em geral, extraindo, a partir da revisão bibliográfica, os aspectos mais bem desenvolvidos de cada uma das áreas de estudo.

Comics and picturebooks have very distinct scholarship traditions that yet arrive at very similar statements regarding their objects due to their formal likeness. We shall argue that both work according to the same medium, that of the graphic narratives, and this paper aids the dialogue between comic studies and children's literature scholarship, as well as drawing concepts from art criticism in order to distinguish between the medium's parameters and conventions. At last, we shall propose parameters for the analysis of graphic narratives at large, based on the more fruitful aspects of each scholarship.

\section{INTRODUÇÃO}

As narrativas que se configuram através do uso sequencial de imagens - e palavras, na maior parte das vezes - são compreendidas pelo termo geral de comics (Kukkonen, 2013; Chute \& DeKoven, 2006). Em sentido amplo, diversos mediums se enquadram nessa definição, logo devemos entender esse termo em sentido estrito: as narrativas gráficas se caracterizam, também, por um processo de leitura tabular. De maneira geral, o medium é constituído pelas capacidades específicas que compõem as possiblidades que um artista pode explorar para criar uma obra (Carroll, 2008).

Em suas instâncias mais radicais, a defesa da especificidade do medium tenta argumentar pela sua pureza, criando um conjunto de regras que não devem ser transgredidas pelo artista. Essa não é a visão que adotaremos: adaptar convenções e dispositivos de outros mediums - a remediação -é, também, um dispositivo à disposição do artista 
(Cf. Kukkonen, 2011). Em suma, um medium implica um conjunto específico de possibilidades e restrições de expressão, e fornecem um repertório próprio de relações e convenções (Pratt, 2009). Enfim, encararemos o medium como o modo que algo nos é apresentado.

O nosso principal objetivo é delinear o medium dos comics e diferenciar entre seus parâmetros e suas convenções. Para tanto, vamos aprofundar nas diferenças entre as duas principais categorias de narrativas gráficas: comics e livros ilustrados. Então, defenderemos que essa distinção se baseia nas convenções de leitura a posição e que "livros ilustrados são narrativas gráficas que operam em um medium conhecido como comics" (Op De Beeck, 2012). Por fim, reuniremos as especificidades do medium para sugerir três parâmetros para a análise das narrativas gráficas em geral: a articulação, a relação texto-imagem e a ordem pictórica.

\section{O MEDIUM E AS ESPECIFICADES DAS NARRATIVAS GRÁFICAS}

As relações de dissonância e consonância que narrativas gráficas estabelecem com outras formas de expressão artística constituem características distintivas que lhe conferem especificidade. Por exemplo, elas continuam uma longa linhagem de discussão das diferentes capacidades da palavra e da imagem que decorrem, pelo menos, desde o iluminista G. E. Lessing (Cf. Kukkonen, 2011) - a simultaneidade da imagem e sua predisposição a representar o espaço em vez de tempo. Assim, as características e convenções construídas ao longo da história da arte são apropriadas por esse meio de expressão.

A sequencialidade caracteriza uma diferença fundamental com relação à pintura, criando implicações específicas das sequência de imagens. Há, todavia, uma relação próxima entre os estudos das narrativas gráficas e da artes visuais. Fresnault-Deruelle (1976[2014]) (Figura 1), por exemplo, faz uma relação explícita entre os comics de Winsor McCay e as pinturas de Cézanne no que diz respeito às tensões entre superfície e profundidade pictóricas, irrompendo a imersão na narrativa. $\mathrm{Na}$ atualidade, o status das narrativas gráficas como forma de arte dificilmente é posto em questão, ganhando cada vez mais espaço de estudo acadêmico (Cf. MFS: Modern Fiction Studies 52-4, 2006; Miller, 2007 p.13-70). 
Figura 1 O conflito entre a superfície da página e a profundidade do espaço em Little Nemo in Slumberland, similar às questões abordadas pela pintura de Cézanne.

Fonte: Sequart. Disponível em: <http://sequart.org/magazine/53203/krazy-kat-vs-littlenemo/>

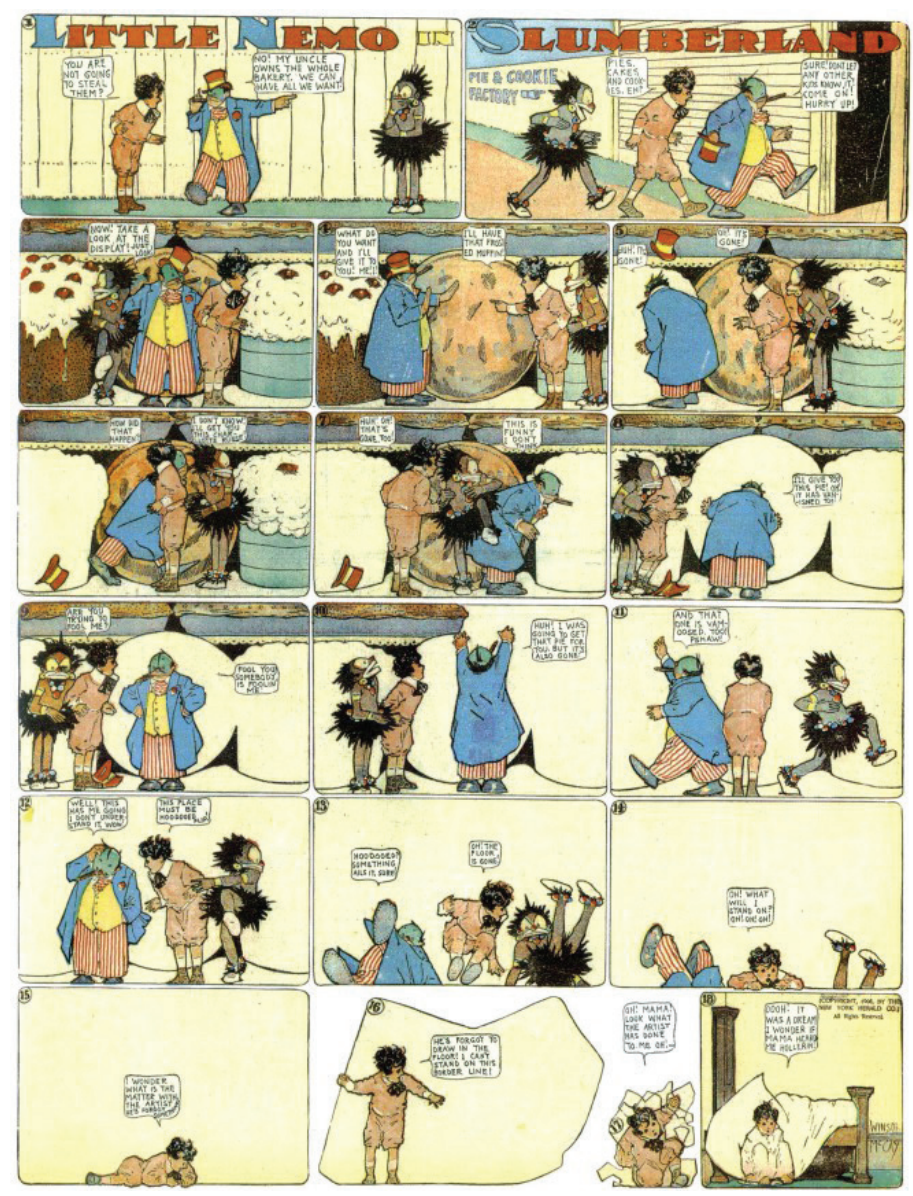

Por outro lado, o cinema também poderia ser considerado uma "narrativa gráfica", por consistir do uso sequencial de imagens e palavras. Todavia, o pericampo caracteriza a diferença fundamental entre o medium do cinema e dos comics (Miller, 2007). Essa noção se baseia na relação espacial das configurações do painel na página: enquanto a imagem do cinema se dá apenas com o espaço dentro da tela - ignorando o que está fora do corte do quadro - nos comics, a imagem será sempre percebida simultaneamente a outras imagens. Além disso, a história e teorias d se desenvolveram de maneira muito distinta; na França, por exemplo, o termo bande dessinée só começou a se diferenciar da vaga palavra "ilustré" a partir da segunda metade do século XX (Miller, 2007).

O espaço da página possibilita aos comics uma mudança fundamental no tipo de leitura: ela foi da linear para a tabular, explicitada nos estudos de comics pelo texto seminal de Pierre Fresnault-Deruelle (1976[2014]). Esse tipo de leitura resulta da 
sobreposição de leituras de diferentes naturezas: a sincrônica do espaço e a diacrônica do tempo. O efeito é exemplar na abertura da página dupla: ela permite a visão simultânea de diversos recortes cronológicos, mas requer uma leitura sequencial. Devido a esse caráter simultâneo, o leitor tem a possibilidade de controlar o tempo de leitura - também diferente do cinema, em que o tempo é uma ferramenta essencial. Por outro lado, devido à sequencialidade, é possível que a narrativa estabeleça um ritmo, representando tempo como espaço na superfície da página (Chute \& Dekoven, 2006).

Nesse universo, há categorias diferenciadas pelos mais diversos fatores: formato, temática, público, ilustração, etc. Os dois grandes grupos de narrativas gráficas são os comics e os livros ilustrados. Vários estudos têm tentado explorar essas diferenças seja explicitando-as, seja atenuando-as ( $C f$. Children's Literature Association Quarterly 37-4, 2012; Sanders, 2013).

Em relação aos aspectos formais, os comics e livros ilustrados são muito próximos, mas possuem convenções muito distintas. Por conseguinte, teorizar as diferenças entre esses objetos não é trivial. A multimodalidade dessas narrativas - a presença de texto e imagem e suas relações - é um dos pontos cruciais em que as teorias coincidem, mas os artefatos divergem: ambos se definem por essa relação, mas isso toma formas distintas nos artefatos. Ou seja, se compararmos comics e livros ilustrados por excelência, eles parecerão muito distintos, mas algo dito sobre a relação texto-imagem em um se aplicará ao outro.

Desse modo, a distinção entre essas categorias se dá antes a partir dos interesses d que se dedicam ao seu estudo: estudos de comic e literatura infantil - o primeiro se fundamenta na semiótica e o outro tem um foco pedagógico. Enquanto o primeiro estuda os comics e graphic novels mais orientados à narrativa e à progressão das ações e eventos - as questões sequenciais - o segundo tende a estudar os livros ilustrados que, quando focam nos aspectos formais, prezam pelas relações mais ambíguas e contemplativas.

Uma vez que nosso enfoque está nas questões em que coincidem, tentaremos reunir a bibliografia mais importante dos dois campos para este estudo. É necessário que ambos façam parte da revisão bibliográfica, pois a complementação entre eles ajuda a elucidar as diversas obras compreendidas pelo medium. Por conseguinte, o objetivo é evitar a descaracterização do objeto, uma vez que algumas narrativas gráficas oscilam entre as convenções que separam comics e livros ilustrados, explorando seus limites e convergências - como os de Shaun Tan ou Brian Selznick.

No entanto, isso requer uma aproximação mais cuidadosa: a forte influência dos estudos em comic da semiologia e da linguística e tendem a adotar uma perspectiva comunicacional e sistêmica da linguagem. Todavia, as narrativas gráficas - como o cinema - não são linguagens em sentido estrito, muito menos uma forma comunicação cotidiana e, assim, a relação estabelecem no mundo não pode ser 
equacionada à da linguagem. A seguir, visamos compreender os componentes e parâmetros que podem ser utilizados para expressão nesse medium.

\section{COMICS E LIVROS ILUSTRADOS: DOIS CASOS DO MESMO MEDIUM}

Nessa seção, argumentaremos que os parâmetros e convenções do medium da narrativa gráfica cria diferentes expectativas de leitura. Para tanto, vamos aprofundar nas diferenças entre as duas principais categorias de narrativas gráficas: comics e livros ilustrados. Então, defenderemos que o medium pode ser analisados formalmente sob os mesmos aspectos, cujas especificidades sugerem seus parâmetros de análise.

Algumas narrativas gráficas são um verdadeiro desafio para a classificação entre comics e livros ilustrados devido aos recursos gráficos e pictóricos, ou às interações de imagens e textos ou à temática das narrativas. Por conseguinte, isso se torna um problema para a teoria: os resultados de formulações teóricas acerca de um podem ser facilmente aplicadas tanto a um como ao outro tipo de artefato, como Sanders (2013) argumenta. Paradoxalmente, delinear as diferenças através dos aspectos formais acaba evidenciando os aspectos que lhes são comuns. Logo, os livros ilustrados e comics não são tão diferentes no que diz respeito à forma.

Sanders (ibid.) retoma a ideia de Barthes de que, na interação entre palavra e imagem, as mensagens linguísticas vão especificar a pluralidade de significados das imagens. Esses fatores implicam também em situações de leitura e uma dinâmica social próprios. Assim, argumenta que a diferença fundamental entre comics e livros ilustrados não está no fato de combinar imagens e mensagens linguísticas, mas em como o artefato antecipa a interação com o(s) leitor(es) e quem são esses leitores. Os livros ilustrados pressupõem ao menos dois leitores: ambos vêem as imagens, mas um lê em voz alta e outro ouve; os comics pressupõem uma leitura solitária e silenciosa.

Esses pressupostos, por sua vez, acarretam leves mudanças formais que nos permite diferenciar os artefatos entre si, mas quando tentam ser teorizadas, começam a se confundir. Em suma, os pressupostos de leitura na criação do artefato implicam em várias características formais fáceis de diferenciar quando materializadas: o tamanho das ilustrações, das sequências, das palavras, da quantidade de texto, o material de impressão. Isso estabelece as convenções dos dois tipos de artefatos. Todavia, uma vez que as características formais artefatos se sobrepõem, confundem-se ao serem teorizadas. Portanto, essas categorias são decorrentes antes das convenções, não das possibilidades de criação de sentido proporcionada pelas obras (Nodelman, 2012). 
Op de Beeck (2012) apresenta essas sobreposições extensamente. De maneira similar a Sanders (2013), conclui que a principal diferença entre comics e livros ilustrados reside no fato de os livros ilustrados serem sempre percebidos como livros infantis ilustrados. Em outras palavras, convenções sociais são atreladas ao medium, preestabelecendo aspectos éticos e sociais - nesse caso, pedagógicos. Pratt (2009) analisa essa tradição como associada à crítica platônica da poesia como ontologicamente inferior à filosofia. No entanto, não há argumentos que possam condenar um medium a uma resposta ética específica; em nosso caso, o livro ilustrado não implica em público infantil. Portanto, ao considerarmos um medium, estamos focando nos meios que ele dispõe para atingir algum fim - que pode ser estético, ético, político, social, pedagógico, etc.

Apesar disso, é fato que os livros ilustrados são percebidos como infantis. Embora não convenha discutir as propriedades que caracterizam a literatura infantil, para nossos propósitos, é necessário que reconheçamos a existência dos dispositivos que remetem a esse público. Essas convenções são evidentes a ponto de serem parodiadas: o livro ilustrado Go the Fuck to Sleep de Adam Mansbach e Ricardo Cortés se apropria delas para fazer um comentário para os pais sobre sua relação com os filhos na hora de dormir. A narrativa ironicamente justapõe os animais, paisagens e metáforas de fábulas tipicamente infantis com súplicas cheias de palavrões e representações inocentemente apocalípticas. Op de Beeck (2012) evidencia que essas convenções são reconhecidas mesmo pelas próprias crianças, pois seu filho de dois anos acreditou que aquele livro era para ele quando o viu.

Os livros ilustrados são objeto de estudo, sobretudo, dos campos de comic studies e da literatura infantil. A revisão bibliográfica do segundo mostra que o campo tende a priorizar os aspectos pedagógicos e culturais, embora hajam estudos acerca das características formais; já os estudos de comics são claramente mais sistemáticos com relação à forma, sobretudo devido à herança estruturalista. Os inúmeros fatores que acarretam nessa distinção são explorados com detalhes por Hunt (2013), mas podem ser sintetizados como uma desconfiança recíproca e um sentimento de propriedade do livro ilustrado pelos dois campos. De qualquer maneira, a sua importância como medium tem sido reconhecido mesmo pelos teóricos tipicamente preocupados com as implicações éticas e pedagógicas como Schwarcz \& Schwarcz (1991).

Consideraremos o livro ilustrado como um tipo de narrativa gráfica que utiliza o medium dos comics. Embora seja relevante estar ciente das convenções das duas categorias de artefatos, diferenciar entre livros ilustrados e comics não será necessário para esse estudo. As características formais que explicitaremos consistem no que há em comum às narrativas gráficas e assim dispensaremos as situações de leitura e de público, buscando evidenciar como essas convenções são convertidas em procedimentos formais na narrativa. 
Adiante, buscamos mapear os parâmetros do medium que podem ser utilizados na obra. Ou seja, os aspectos relevantes para este estudo consistem nos parâmetros disponíveis pelo medium que a obra é capaz articular. Assim, não é do escopo, por exemplo, que leitor a obra presume, mas quais convenções ela pode se apropriar e utilizar para sua narrativa. Nossa principal bibliografia será oriunda dos comic studies franceses, com contribuições dos teóricos de livros ilustrados e da crítica de arte.

\section{PARÂMETROS PARA ANÁLISES DE NARRATIVAS GRÁFICAS}

\subsection{Artrologia}

A articulação se origina nos estudos do que Groensteen (2007) chama de artrologia, que propõe uma teoria para compreender como a sequencialidade permite a criação de sentido no medium dos comics. Ele divide em três níveis: o código espaço-tópico (superfície da página-dupla), a artrologia restrita (sequência linear) e a artrologia geral (série não-linear).

O código espaço-tópico diz respeito à superfície da página-dupla, ou hiperpainel. O diferencial das narrativas gráficas é que cada painel conta com o pericampo para a leitura: conforme mencionado, no cinema, apenas o espaço da tela é visto, enquanto nos comics, a simultaneidade das outras imagens presentes no hiperpainel guiam a leitura de cada painel individualmente. De maneira resumida, Miller (2009) estabelece como as principais possibilidades desse código como: 1) o tamanho, formato e posição dos painéis, 2) a incrustação, 3) a sarjeta e 4) os padrões de configuração da página. Esses fatores jamais operam isoladamente, uma vez que o espaço da página-dupla é limitado; a opção por cada um deles irá implicar em restrições para outro e para outras páginas duplas, condicionando os outros níveis.

Vamos compreender o código espaço-tópico dialeticamente entre o espaço ocupado e o espaço em branco; isso confere maior importância à sarjeta - essencialmente, o espaço em branco que compõe as elipses do medium - para a análise do livro ilustrado. Portanto a incrustação se caracteriza pela superposição de painéis - ausência de espaço em branco - as propriedades dos painéis serão discutidas em relação à própria configuração da página (Figura 2). 
Figura 2 Apesar de Sergio Toppi não desenhar ou separar cada um dos quadros, o uso do espaço preto e branco nos permite comprender a sequencialidade da página nesse exemplo de Sheraz-de. Fonte: ACalopsia. Disponível em: <www.acalopsia.com/sharaz-de-as-mil-e-uma-noites-de-sergiotoppi/>

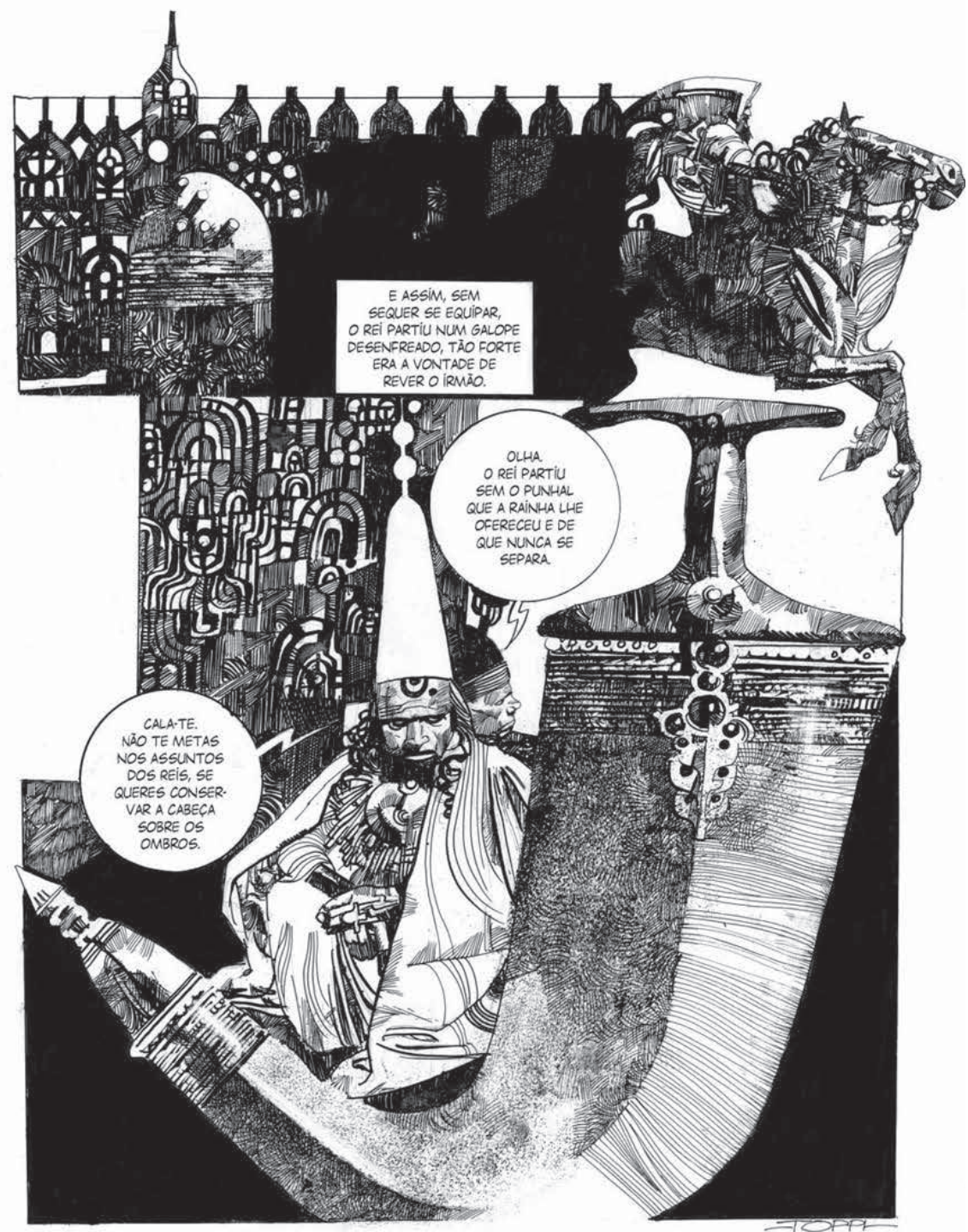

Já a artrologia restrita diz respeito a como esses painéis se articulam de maneira linear para criar a sequência narrativa (Figura 3) - e aqui, aproximações com a narrativa cinematográfica são pertinentes. Miller (2009) sintetiza essas relações em 1) espaço entre-quadros e em 2) variações estilísticas, que podemos associar ao cinema como equivalentes à função do corte e do enquadramento, respectivamente. A lacuna espaço-temporal que a sarjeta permite é indeterminada, bem como o corte da linguagem cinematográfica; as 
escolhas de enquadramento, ângulo, composição e cor também são compartilhadas pelo cinema, e são associadas à tradição pictórica da história da arte.

Figura 3 A página-dupla de Asterios Polyp nos mostra a relação sequencial dos eventos mesmo sem uma estrutura modular mais comum nos comics. Ainda assim, a composição e os "cortes" entre cada cena nos permitem compreender a sua sequencialidade.

Fonte: Mazzucchelli, David. Asterios Polyp. Pantheon, 2009.

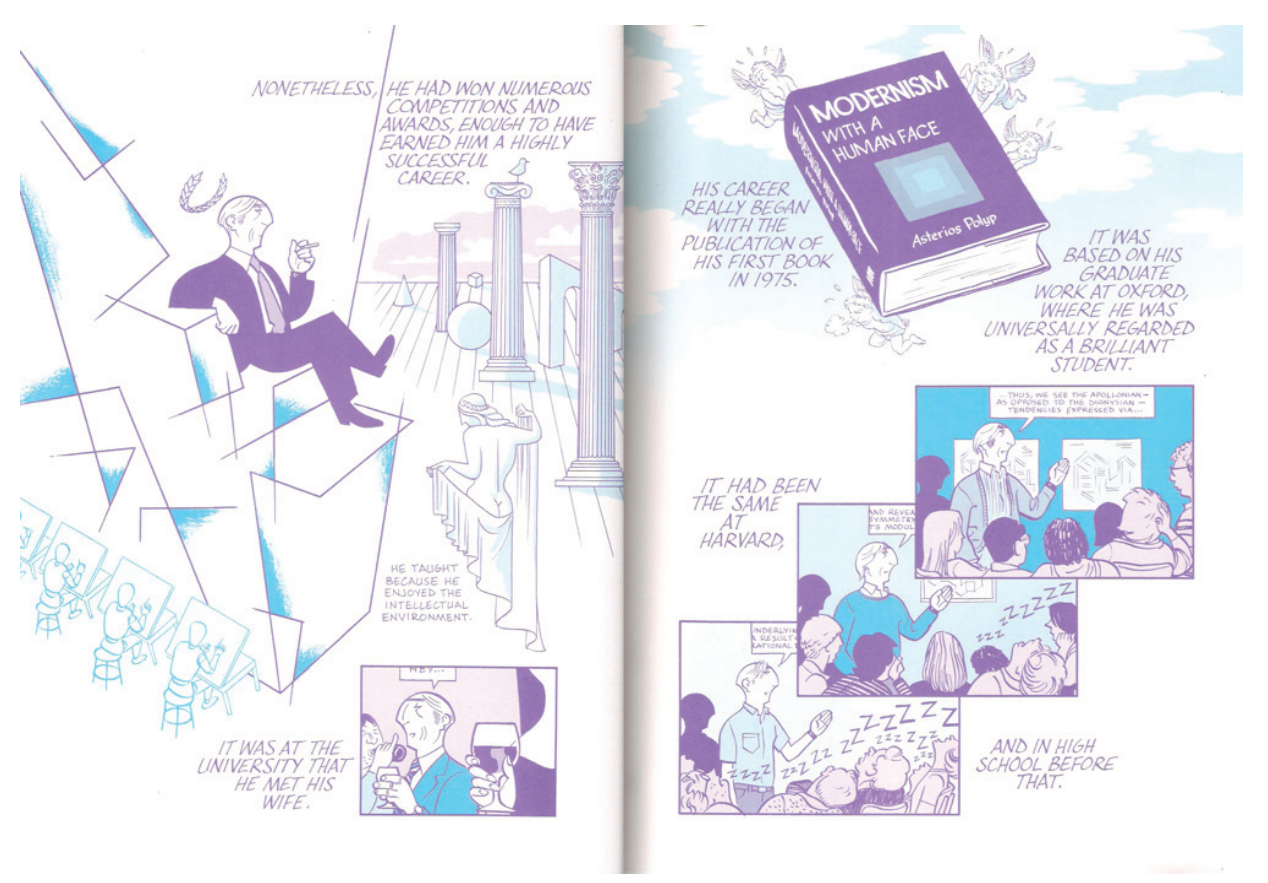

A artrologia geral, por sua vez, diz respeito às relações não-lineares presentes nas imagens apresentadas pela narrativa gráfica. Groensteen (2007) se refere a esse tipo de relação como séries, em oposição às sequências da artrologia restrita. Uma vez que tentamos nos distanciar do vocabulário semiológico, nós podemos entender essas relações como um leitmotif gráfico da narrativa: uma determinada relação pictórica que se repete de maneira não-linear para evocar uma resposta do leitor (Figura 4). 
Figura 4 Essas duas páginas de A Árvore Vermelha de Shaun Tan acontecem no início e no fim da narrativa, repetindo a estrutura da página para remeter a um ambiente em vez de uma sequência.

Fonte: Elaborado pelos autores a partir de TAN, Shaun. El árbol rojo. Bárbara Fiore, 2005.

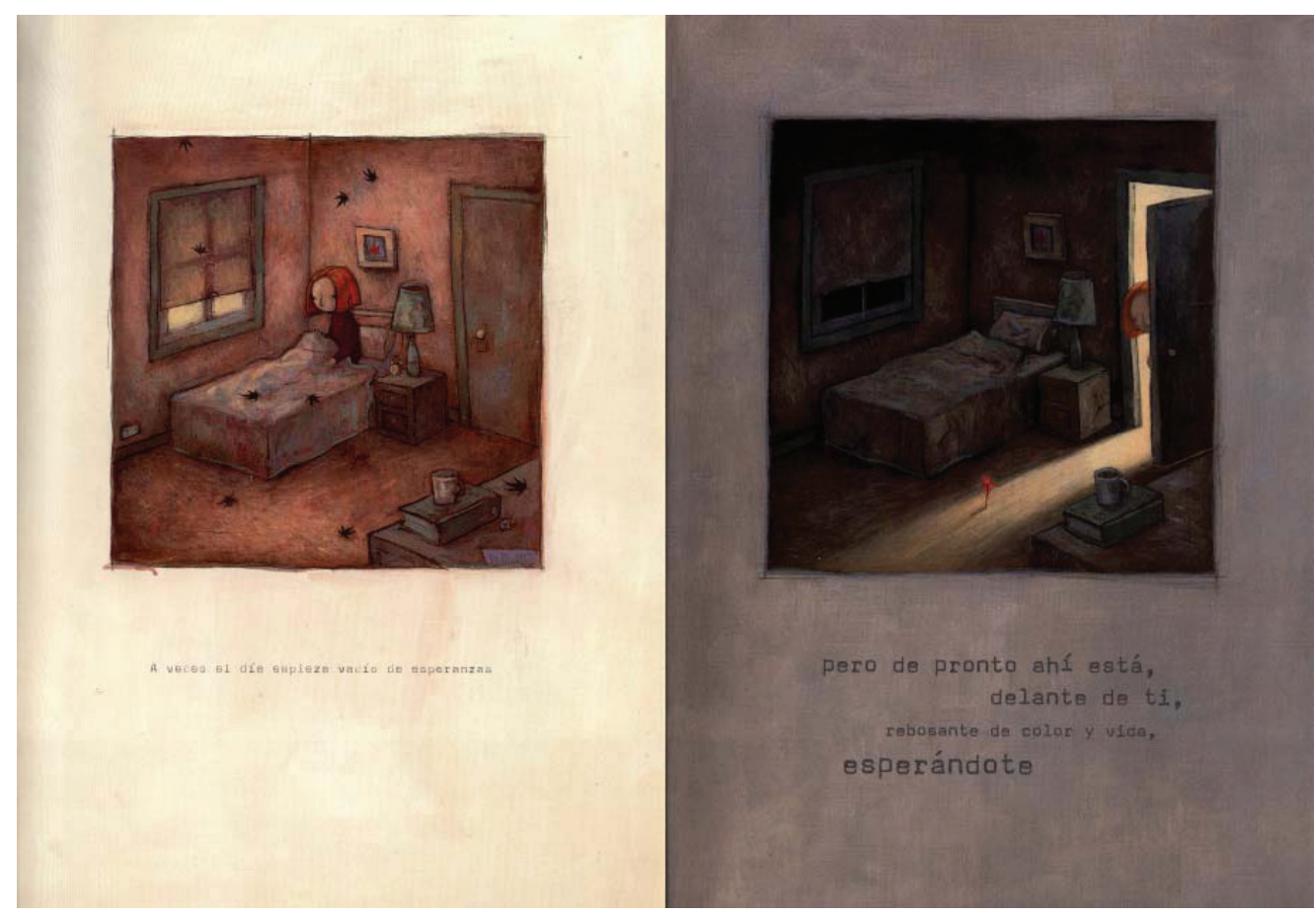

\subsection{Multimodalidade}

Apesar de comics e livros ilustrados se definirem por essa relação, esse é um dos principais pontos em que as categorias se diferenciam, pois os comics utilizam uma série de códigos e convenções específicas, enquanto a maioria dos livros ilustrados tendem a apresentar uma narrativa textual "descolada" da narrativa pictórica para ser contada por um leitor. No entanto, essas convenções têm se misturado cada vez mais (Hatfield \& Svonkin, 2012), embora o foco das pesquisas contrastem. Por fim, a revisão bibliográfica mostrou que os estudos dos livros ilustrados contemporâneos têm evidenciado relações interpretativas mais complexas entre texto e imagem.

Os estudos de comics, em geral, derivam suas ponderações do artigo de Barthes A retórica da imagem de 1964, em que defende duas principais relações entre imagem e texto: ancoragem e revezamento. Groensteen (2007) comenta que não há uma distinção clara entre a imagem isolada e a imagem sequencial, mas evidencia que a função de revezamento dos diálogos nos comics contextualiza e avança a narrativa. A função de ancoragem é minimizada, uma vez que a 
imagem sequencial não seria polissêmica, pois o próprio sistema dos comics ancora seu significado.

O texto tem ainda a função de temporalidade e ritmo, uma vez que os balões de fala ajudam a dimensionar a velocidade de uma ação em um quadro. Miller (2009) fala ainda da integração do texto feito à mão nos comics e de sua expressividade; as onomatopeias, por exemplo, servem como "sons pictóricos". Todavia, não há ênfase no estudo das relações entre texto e imagem: apenas é orientado ao avanço a ação, como postulado por Baetens \& Lefèvre (1993) no princípio da economia narrativa.

Por outro lado, nos livros ilustrados, essa questão ganha uma amplitude maior: Nikolajeva \& Scott (2006) investigam o nível de leitura que surge a partir da interação do verbal e pictórico. No entanto, não há homogeneidade nem nos termos utilizados para descrever esse nível, nem nas categorias de relações que apresentam. Apesar de reconhecerem que o conceito de iconotexto também não é suficiente, ele é utilizado ao longo da investigação da ampla diversidade de dinâmicas nos livros do espectro entre palavras e imagens. Portanto, esse conceito é tornado fundamental para o estudo dos livros ilustrados contemporâneos, em que essas relações de esclarecimento tem dado lugar à ambiguidade e abertura das narrativas.

Assim, a questão das nomenclaturas se tornam um tanto mais problemáticas, sendo possível subdividir ainda mais essas categorias. Por exemplo, elas apresentam diversos livros ilustrados premiados em que o texto é independente da ilustração, constituindo uma relação simétrica que caracterizaria um livro com ilustração. Por outro lado, nas obras de um autor-ilustrador, as relações são complementares, constituindo uma estilo de prosa mais peculiar - um livro ilustrado.

O ponto central, enfim, são os livros ilustrados em que as relações entre texto e imagem tomam uma dimensão mais complexa: em casos que o distanciamento entre eles permite que o processo de leitura seja mais iterativo e os significados sejam construídos a partir da tensão entre o pictórico e o verbal. São as relações definidas como reforço e contraponto. Alguns livros ilustrados contemporâneos criam disparidades entre a narrativa verbal e a pictórica, permitindo o surgimento de um iconotexto complexo e ambíguo em diversos graus.

A partir dessa gama de possibilidades de interpretação e interação surgem uma variedade de alternativas de modalidades do iconotexto. Nikolajeva \& Scott (2006) se apropriam dessa noção linguística que permite averiguar a condição de verdade de uma afirmação para avaliar em que medida uma narrativa é efetivamente mimética ou simbólica - em oposição às categorias de fantasia e realidade. Assim, múltiplas modalidades emergem desde o reforço entre imagem e texto - a modalidade indicativa simétrica - até as diversas variações de ambiguidades não resolvidas, em que não é possível confirmar nem o que é narrado pela imagem, nem pelo texto. 


\subsection{Ordem pictórica}

Os parâmetros pictóricos são pouco evidenciados pelos estudos das narrativas gráficas. Como apontado por Gardner (2011), essa dimensão não é teorizada pelos comic studies com frequência, apesar de ser um elemento básico e fundamental para a expressividade do medium. Já os estudos de literatura infantil tendem a enfatizar a variedade nos livros ilustrados, devido à pluralidade de representações e técnicas.

Essa dimensão é vulgarmente reconhecida como o "estilo do desenho". Gardner (2011) teoriza sobre a linha nos comics para evidenciar que estilo não é apenas um aspecto "para caracterização ou formato narratorial mas uma maneira de codificar modos de alinhamento, oposição, e conflito operando também em outros níveis da estrutura narrativa” (Herman, 2002). A narrativa gráfica jamais consegue esconder o trabalho mecânico da representação que a torna visível (Gardner, 2011).

Assim, ao contrário do cinema, que possui uma tradição em tentar imergir o espectador a ponto de tentar apagar a percepção da obra construída como tal, as narrativas gráficas jamais podem se esquecer do medium, ou torna-lo transparente; não apenas pelo desenho, mas pelos quadros, espaços em branco, textos (à mão). Assim, ele defende que a dimensão pictórica - a linha - faz com que as narrativas gráficas se aproximem mais da performance oral do que o filme ou o romance por ser modulado tanto pelo que é técnico, fisiológico, da experiência e da história que está sendo contada.

No campo dos livros ilustrados, diversos estudos como os de Moebius (1986), Schwarcz \& Schwarcz (1991) e Kiefer (1992) tentam criar uma gramática para o entendimento das imagens e das sequências. Entretanto, a mera ideia de criar uma gramática - e, em certa medida, o mero termo de linguagem gráfica - é uma maneira de submeter a visualidade ao regime de pensamento verbal (Salisbury \& Styles, 2012), criando categorias sintáticas e semânticas para a imagem. Embora nos ajude a falar sobre a imagem, não vamos adotar essa perspectiva no nosso estudo, pois enfatizaremos os aspectos pictóricos como dispositivo artístico dentro da obra. Assim, consideraremos que a imagem está intimamente relacionada à narrativa e que sua presença altera todo seu significado por proporcionar a criação do iconotexto.

Sob outra perspectiva, Van der Linden (2011) é clara em evidenciar que os livros ilustrados "já não tem limites em termos de tamanho, materialidade, estilo ou técnica, e toda sua dimensão visual, inclusive tipográfico, é em geral elaboradíssima”. Assim, seu livro apresenta o máximo de dispositivos artísticos que os ilustradores utilizam para criar suas narrativas, proporcionando, ao mesmo tempo, discussão teórica e um longo catálogo de exemplos. Tampouco é nosso intuito refazer esse trabalho a fim de buscar uma linguagem comum aos livros ilustrados, uma vez que reconhecemos essa pluralidade. 
Apesar de reconhecermos as possibilidades ilimitadas do medium, há uma característica que as permeia, aqui compreendidas através do conceito de ordem pictórica explicitado por Michael Baxandall (2006) na análise de pinturas. Em síntese, esse princípio defende que ao falar sobre uma obra visual não se deve perder a ostensividade com ela; é necessário que a crítica seja demonstrativa, a fim de explicitar as características da imagem. Em outras palavras, considerações acerca dos aspectos pictóricos do medium devem ser dirigidas a ilustrações e pinturas específicas. Devido a isso, todos os estudos citados se utilizam de exemplos para evidenciar elementos como forma, cor, ritmo, composição, linha. Logo, acreditamos que a tentativa de elaborar uma gramática é vaga.

Portanto, essa dimensão não vai contar com categorias ou tentativas de estabelecer uma gramática. Antes, visa evidenciar a prioridade que será dada ao que é apresentado pela obra. Além disso, é importante não deixarmos que os aspectos sequenciais e textuais sobreponham a dimensão pictórica, como Gardner (2011) argumenta que aconteceu nos comics. Estaremos interessados, ao analisar essa ordem pictórica, nos diálogos que as ilustrações criam com a história da arte, as técnicas de execução, as propriedades (composição, cor, tonalidades) e o clima que elas estabelecem para a narrativa, entre outras características que podem emergir ao discutirmos as imagens em específico.

\section{CONCLUSÃO}

Embora os livros ilustrados e os comics sejam artefatos distintos, eles compartilham dos mesmos parâmetros para contar uma história. Entretanto, o que é amplamente variável é o modo como eles utilizam esses parâmetros e os transformam em procedimentos: os mais significantes na narrativa são proeminentes no primeiro plano e os demais se submetem e se adequam.Desse modo, conforme definidos nesse artigo, esses parâmetros são vagos o suficiente para se moldar aos objetos de análise, priorizando o que cada obra traz de singular para o medium e para o leitor.

As categorias dos artefatos, como vimos, é menos importante. Se uma convenção social determina essa categoria, a análise seria de outra natureza, a partir de outros parâmetros. Para nossas considerações formais e interpretativas, a artrologia, a multimodalidade e a ordem pictórica das narrativas gráficas nos parecem os aspectos mais fundamentais e passíveis de significação do medium. Por conseguinte, esses parâmetros gerais devem ser testados em casos específicos a fim de explicar a obra sem que a submeta a uma moldura teórica pré-estabelecida. 


\section{REFERÊNCIAS}

BAETENS, Jan \& LEFÈVRE, Pascal (1993). The Work and its Surround. Em: MILLER, Ann \& BEATY, Bart (eds) (2014). The French Comics Theory Reader. Leuven: Leuven University Press.

BAXANDALL, Michael. 2006. Padrões de Intenção: A explicação histórica dos quadros. São Paulo: Companhia das Letras.

CARROLL, Noël. 2008. The philosophy of Motion Pictures. Malden: Blackwell Publishing

CHUTE, Hillary L. \& DEKOVEN, Marianne. 2006. Introduction: Graphic Narrative. MFS Modern Fiction Studies, Volume 52, Number 4, Winter 2006, pp. 767-782 (Article)

FRESNAULT-DERUELLE, Pierre. 1976. From Linear to Tabular. Em MILLER, Ann \& BEATY, Bart (eds). 2014. The French Comics Theory Reader. Leuven: Leuven University Press.

GARDNER, Jared. 2011. Storylines. Em SubStance, Volume 40, Number 1, 2011 (Issue 124), pp. 53-69 (Article).

GROENSTEEN, Thierry. 2007. The System of comics. Traduzido por Bart Beaty e Nick Nguyen. Mississipi: University Press of Mississipi.

HATFIELD, Charles \& SVONKIN, Craig. 2012. Why Comics Are and Are Not Picture Books: Introduction. Children's Literature Association Quarterly, Volume 37, Number 4, Winter 2012, pp. 429-435 (Article)

HERMAN, David. 2002. Story Logic: Problems and Possibilities of Narrative. Nebraska: University of Nebraska Press.

KIEFER, Barbara. 1992. Visual Criticism and Children's Literature. Em B. Hearne and R. Sutton (eds) Evaluating children's books : a critical look : aesthetic, social, and political aspects of analyzing and using children's books (Papers presented at the Allerton Park Institute held October 25-27, 1992): 73-91.

KUKKONEN, Karin. 2011. Comics as a Test Case for Transmedial Narratology. SubStance, Volume 40, Number 1, 2011 (Issue 124), pp. 34-52 2013. Studying comics and graphic novels. Oxford: Wiley Blackwell.

LINDEN, Sophie Van der. 2006. Para ler o livro ilustrado. São Paulo: Cosac Naify. MILLER, Ann. 2007. Reading bande dessinée: Critical Approaches to Frenchlanguage Comic Strip. Bristol, UK/Chicago, USA: intellect.

MOEBIUS, William. 1986. Introduction to picturebook codes. Word \& Image: A Journal of Verbal/Visual Enquiry, 2:2, 141-158.

NIKOLAJEVA, Maria \& SCOTT, Carole. 2006. Livro Ilustrado: Palavras e Imagens. São Paulo: Cosac Naify.

NODELMAN, Perry. 2012. Picture Book Guy Looks at Comics: Structural Differences in Two Kinds of Visual Narratives. Children's Literature Association Quarterly, Volume 37, Number 4, Winter 2012, pp. 436-444 (Article)

OP DE BEECK, Nathalie. 2012. On Comics-Style Picture Books and PictureBookish Comics. Children's Literature Association Quarterly, Volume 37, Number 4, Winter 2012, pp. 468-476 (Article) 
PRATT, Henry John. 2009. Medium Specificity and the Ethics of Narrative in Comics. StoryWorlds: A Journal of Narrative Studies, Volume 1, 2009, pp. 97113 (Article)

SALISBURY, Martin \& STYLES, Morag. 2012. Livro Infantil ilustrado: A arte da narrative visual. São Paulo: Rosari.

SANDERS, Joe Sutliff. 2013. Chaperoning Words: Meaning-Making in Comics and Picture Books. Children's Literature, Volume 41, 2013, pp. 57-90 (Article)

SCHWARCZ, Joseph, \& SCHWARCZ, Chava. 1991. The picture book comes of age. Chicago, IL: American Library Association.

\section{Sobre os autores}

Eduardo A. Souza (mestre)

souza.edrd@gmail.com

Centro de Artes e Comunicação

Programa de Pós-graduação em Design

Departamento de Design

Universidade Federal de Pernambuco

\section{Eva Rolim Miranda (Phd)}

<evarolim@gmail.com>

Centro de Artes e Comunicação

Programa de Pós-graduação em Design

Departamento de Design

Universidade Federal de Pernambuco

\section{Gentil Porto Filho (Phd)}

<gentilp@uol.com.br>

Centro de Artes e Comunicação

Programa de Pós-graduação em Design

Departamento de Design

Universidade Federal de Pernambuco

Edição especial P\&D2016

Artigo recebido em 23/09/2016

Artigo aceito em 30/09/2016 